Syntax Literate: Jurnal Ilmiah Indonesia p-ISSN: 2541-0849

e-ISSN: 2548-1398

Vol. 5, No. 7, Juli 2020

\title{
FAKTOR EKSTERNAL YANG MEMPENGARUHI DINAMIKA WACANA AMANDEMEN PASAL 9 UNDANG-UNDANG DASAR JEPANG 1947 (PERIODE 2010-2016)
}

\section{Igat Meliana}

Prodi Bahasa Jepang, Sekolah Tinggi Bahasa Asing Cipto Hadi Pranoto

Email: igatmeliana240@gmail.com

\section{Abstract}

This article will focus about external factors influence the dynamics of the discourse of the amendment of Article 9 of the Japanese Constitution period 20102016, namely the United States pressure, the economic and military rise of China and the threat of North Korea. The Japanese prime minister used global security threat issues to encourage Japanese security police in order to amend article 9 of Constitution 1947that had been rejected by Japanese residents who did not want Japan to have legitimate military power. The Japan's remilitarization also gained attention from countries in the East Asia region due to Japanese history during World War II. On the other side, U.S. hegemony that began to fade encouraged Japan to be self-reliant in security that had been supported by the United States. And North Korea missile test activities also influenced the discourse amendment of Article 9. This research is a qualitative research with literature method. And the results of this study indicate that the dynamics of the discourse of Article 9 Constitution revision is affected by the perception of the level of threat and vulnerability of the United States, the rise of the Chinese economy and military, and the threat of North Korea. China and North Korea as well as countries in the region that do not want Japan to rearm, pushing people to opposed towards the amendment discourse.

Keywords : Article 9, the Constitution of Japan, External Factors

\section{Abstrak}

Penelitian ini membahas mengenai faktor eksternal yang mempengaruhi dinamika wacana amandemen Pasal 9 Undang-Undang Dasar Jepang 1947 periode 20102016. Faktor eksternal yang mempengaruhi adalah tekanan Amerika Serikat, kebangkitan ekonomi dan militer Tiongkok dan ancaman Korea Utara. Tekanan dari luar atau gaiatsu turut mempengaruhi dinamika wacana amademen pasal 9 Undang-Undang Dasar Jepang 1947 di level domestik. Perdana Menteri Jepang menggunakan isu-isu ancaman keamanan global untuk mendorong kebijakan Jepang dalam bidang keamanan agar mengamandemen Pasal 9 Undang-Undang Dasar 1947 yang selama ini mendapat penolakan dari penduduk Jepang yang tidak menginginkan Jepang kembali mempunyai kekuatan militer. Remiliterisasi negara Jepang juga mendapat perhatian dari negara-negara di Kawasan Asia Timur disebabkan sejarah Jepang pada Perang Dunia II. Di lain pihak, hegemoni Amerika Serikat yang mulai memudar mendorong Jepang agar dapat mandiri dalam bidang 
keamanan yang selama ini mendapat dukungan dari Amerika Serikat. Dan aktifitas uji coba rudal Korea Utara pun turut mempengaruhi wacana amandemen Pasal 9. Penelitian ini merupakan penelitian kualitatif dengan metode kepustakaan. Hasil penelitian ini menunjukan bahwa dinamika wacana amandemen Pasal 9 dipengaruhi oleh presepsi tingkat ancaman dan kerawanan dari Amerika Serikat, kebangkitan ekonomi dan militer Tiongkok, dan ancaman Korea Utara. Kerawanan mendorong sikap pro masyarakat Jepang, namun di sisi lain adanya ketakutan terhadap memburuknya hubungan Jepang dengan Tiongkok dan Korea Utara serta negara-negara di kawasan yang tidak ingin Jepang membangun kekuatan militer kembali, mendorong sikap kontra masyarakat terhadap wacana amandemen.

Kata kunci: Article 9; the Constitution of Japan; External Factors

\section{Pendahuluan}

Pasca Perang Dunia II, Jepang ditekan untuk tunduk pada 13 butir deklarasi Potsdam yang mendorong Jepang untuk mencantumkan Pasal 9 Undang-Undang Dasar Jepang. Proses perumusan Undang-Undang Dasar Jepang yang digunakan tahun 1947 mendapat tekanan dari Amerika Serikat. Bunyi Pasal 9 Undang-Undang Dasar Jepang 1947 adalah sebagai berikut:

\section{“第九条 日本国民は、正義と秩序を基調とする国際平和を誠実に希求し、 国権の発動たる戦争と、武力にたる威嚇又は武力の行使は、国際紛争を解決 する手段としては、永久にこれを放棄する。 前項の目的を達するため、陸海空軍その他の戦力は、これを保持しない。国 の交戦権は、これを認めない” (National Diet Library,1947)}

"Pasal 9 Rakyat Jepang, bertekad dengan sungguh-sungguh menciptakan keamanan internasional berdasarkan keadilan dan tata tertib, selamanya menolak perang sebagai hak Negara yang berkuasa dan ancaman atau penggunaan pasukan bersenjata sebagai penyelesaian perselisihan international. Untuk melengkapi tujuan dari paragraf sebelumnya, pasukan darat, pasukan laut, dan pasukan udara, seperti semua yang berpontensial menimbulkan perang, tidak akan pernah dipelihara. Hak Negara untuk berperang tidak akan diakui."

Pasal 9 melarang Jepang untuk memiliki kekuatan militer baik secara defensif maupun ofensif. Akan tetapi tahun 1950-an Pemerintah Jepang mereinterpretasi Pasal 9 agar dapat membentuk Pasukan Bela Diri Jepang (Jietai atau Self Defense Force) pada 10 Agustus 1950 untuk membantu Amerika Serikat dalam Perang Korea.

Wacana amandemen Pasal 9 mulai mengemuka sejak saat itu. Sebelum tahun 1990'an wacana amandemen Pasal 9 tabu untuk diperbincangkan tetapi sejak pembentukan Dewan Penelitian Undang-Undang Dasar di tingkat Parlemen oleh Obuchi Keizo pada 1999 wacana amandemen semakin menjadi perdebatan di level domestik Jepang.

Pasca perang dingin sistem internasional berubah dari bipolar menjadi multipolar sehingga turut mempengaruhi Jepang di kawasan Asia Timur. Jepang dihadapkan oleh 
kemajuan ekonomi dan militer Tiongkok serta rudal nuklir Korea Utara. Sebagai Sekutu Amerika Serikat, Jepang didorong untuk membangkitkan militernya kembali untuk menadingi kemajuan militer Tiongkok yang telah mengancam hegemoni Amerika Serikat di kawasan Asia Timur.

Selain itu, warga negara Jepang juga merasakan ancaman terhadap Korea Utara yang sedang melakukan uji coba nuklir dan tidak taat dengan peraturan internasional. Korea Utara pernah secara langsung mengancam keamanan warga negara Jepang dengan adanya kasus penculikan warga Jepang dari tahun 1948. Isu nuklir Korea Utara menjadi sangat penting bagi Jepang karena pemerintah Jepang merasa keamanan negaranya terancam karena letak geografis yang berdekatan, serta faktor historis kelam Jepang pada Perang Dunia II (Widyasari, 2014).

Pada 2016, Korea Utara telah berhasil melakukan peluncuran rudal balistik sampai ke wilayah perairan Jepang (Hyodo, 2017). Ancaman masyarakat Jepang terhadap uji coba nuklir dan rudal Korea Utara sehingga pada Maret 2016, digelar latihan simulasi jika rudal sampai ke Zona Ekonomi Eksklusif Jepang (Oh, 2016).

Selain Korea Utara, Tiongkok juga mengancam keamanan Jepang. Kemajuan Ekonomi dan militer Tiongkok mengancam Jepang sebagai negara yang mempunyai sejarah yang panjang dengan Tiongkok. Perebutan wilayah di Laut China Selatan, fakta sejarah tentang zaman pendudukan Jepang seperti isu Jugun Ianfu (Comfort Women) atau buku teks sejarah adalah isu-isu yang sensitif untuk hubungan diplomatik kedua negara. Hubungan Tiongkok dan Jepang mulai dinormalisasi pada 1972 hingga pada masa Perdana menteri Junichro Koizumi pada 2001 hubungan Jepang dan Tiongkok kembali memanas. Pada 2004 dan 2005 di Tiongkok marak demonstrasi yang dilakukan kepada warga negara Jepang di Tiongkok yang memperburuk hubungan antara kedua negara. Pada 2006, setelah Perdana Menteri Koizumi Lengser dan digantikan oleh Perdana Menteri Shinzo Abe, Perdana Menteri Abe melakukan kunjungan kenegaraan ke Tiongkok kemudian ketegangan antara kedua negara kembali mencair. Hingga pada 2010 peristiwa penangkapan kapal nelayan ikan Tiongkok oleh Pasukan Penjaga Pantai Jepang (Japan Coast Guard) semakin mepertinggi ketegangan antara kedua negara terkait konflik wilayah Laut Cina Timur (Smith, 2016).

Selain Tiongkok, hubungan Amerika-Jepang turut pula mempengaruhi keamanan Jepang di level domestik. Hubungan Amerika-Jepang yang erat dimulai setelah Perang Dunia II berakhir. Pasca Perang Dunia II, keamanan Jepang dibawah payung AS. Sejalan dengan kemajuan Jepang dalam bidang Ekonomi, Amerika Serikat menginginkan Jepang untuk berbagi beban (burden sharing) dengan Amerika Serikat dalam bidang keamanan, terutama di wilayah Asia Pasifik. Apabila Jepang berhasil mengamandemen pasal 9 Undang-Undang Dasar Jepang 1947 maka akan ikut mempengaruhi hubungan Jepang dengan negera-negara di kawasan (khususnya Asia Timur) dan juga akan meningkatkan ketenggangan dengan Tiongkok.

Pertanyaan penelitian ini adalah faktor apa sajakah yang mempengaruhi wacana amandemen Pasal 9 Undang-Undang Dasar Jepang 1947? Penelitian ini bertujuan memberikan analisis tentang pengaruh faktor eksternal dalam dinamika isu di level 
domestik. Terkait penelitian ini akan ditunjukan pengaruh faktor eksternal dalam dinamika wacana amandemen Pasal 9 Undang-Undang Dasar Jepang 1947.

Teori yang digunakan dalam penelitian ini adalah teori ancaman dan kerawanan dari Barry Buzan dan teori dilema keamanan dalam aliansi dari Glenn H. Snyder. Serta Gaiatsu dalam Two Level Games yang dipaparkan oleh Kevin Cooney.

\section{Metode Penelitian}

Penelitian ini merupakan penelitian kualitatif dengan metode deskriptif analitis. Teknik pengumpulan data yang digunakan melalui studi pustaka, dokumen resmi, buku, jurnal ilmiah, artikel, surat kabar, laporan penelitian, dan sumber-sumber lainnya. Pada penelitian ini disajikan data survey atau hasil jajak pendapat berupa angka adalah data pendukung argumen dalam penelitian ini.

\section{Hasil dan Pembahasan}

\section{A. Hasil Penelitian}

Hasil Penelitian ini adalah dinamika wacana amandemen yang mempengaruhi tingkat ancaman dan kerawanan dari proses Jepang mendorong sikap pro masyarakat Jepang wacana pasal 9, namun di sisi lain kelompok-kelompok yang tidak mendukung wacana amandemen Pasal 9 Undang-Undang Dasar Jepang 1947 menganggap bahwa militerisasi Tiongkok dijadikan dasar untuk mengamandemen karena semakin memicu kerawanan dan keamanan di kawasan.

Dari keseluruhan temuan dapat dilihat dalam konteks keamanan sangat bergantung pada kondisi eksternal. Keamanan Jepang teracaman dengan kemajuan militer dan ekonomi Tiongkok yang diperkirakan akan menjadi negara adikuasa. Jepang dan Tiongkok menghadapi masalah perebutan kepulauan Senkaku yang mendorong krisis kepercayaan baik dari masyarakat Jepang maupun Masyarakat Tiongkok.

Berdasarkan situasi hubungan antara Jepang dan Korea Utara, isu penculikan yang kontraproduktif dan semakin meningkatnya uji coba rudal dan nuklir oleh Korea Utara dapat menambah ketengangan hubungan Jepang dan Korea Utara. Dengan adanya Pasal 9 Undang-Undang Dasar Jepang 1947, Jepang diperbolehkan memiliki militer sebatas untuk mempertahankan diri. Sedangkan Korea Utara memiliki nuklir dan rudal balistik yang telah sampai ke wilayah perairan Jepang.

Jepang mengalami dilema aliansi tahap kedua terhadap Amerika Serikat yang mempengaruhi pemikiran masyarakat Jepang untuk kontra dengan wacana amandemen pasal 9 Undang-Undang Dasar Jepang 1947. Jika Jepang mengamandemen Pasal 9 Undang-Undang Dasar Jepang 1947 yang menjadikan Jepang mempunyai militer maka akan memperbesar probabilitas Jepang untuk berperang dengan Tiongkok karena perebutan kepualauan Senkaku. Sedangkan Amerika Serikat Sedang mengalami kemunduran hegemoni dan krisis ekonomi. 
Di sisi lain, Hegemoni Amerika Serikat di dunia mengalami kemunduran pasca tragedi 9/11. Keterlibatan Amerika Serikat pada Perang Afganistan dan Iraq telah menghabiskan energi dan waktu Amerika Serikat. stagnansi pertumbuhan Ekonomi Amerika Serikat menyebabkan krisis ekonomi yang dialami oleh Amerika Serikat. Di tengah kondisi Amerika Serikat yang mulai kehilangan kekuatannya, mayoritas masyarakat Jepang masih percaya untuk menjadikan Amerika Serikat sebagai sekutu. Walau pun demikian, sebagian masyarakat tidak menginginkan Jepang untuk menjadi negara yang memiliki militer dan berlindung di bawah payung keamanan Amerika Serikat.

\section{B. Pembahasan}

Faktor eksternal yang mempengaruhi wacana amandemen Pasal 9 UndangUndang Dasar Jepang 1947 adalah tekanan Amerika serikat, Kemajuan Ekonomi dan Militer Tiongkok dan Ancaman Korea Utara. Sedangkan indikator faktor eksternal yang mempengaruhi wacana amandemen Pasal 9 Undang-Undang Dasar Jepang 1947 adalah ketidakpastian hegemoni AS, masalah kepulauan Senkaku, konflik Laut China Selatan, OBOR/BRI, isu Penculikan dan agresivitas Uji coba nuklir dan peluncuran misil balistik rezim Kim Jong-Un.

Pada 2008, Amerika Serikat mengalami krisis keuangan yang mempengaruhi perekonomian dunia. Menurut data statistik dari Biro Tenaga Kerja Kementrian Tenaga Kerja Amerika Serikat, terjadi peningkatan jumlah prosentase pengangguran yang signifikan mulai tahun 2008 dan mencapai puncak pada tahun 2010 (Statistics, 2012).

Hubungan Jepang dan Amerika Serikat mengalami dilema aliansi seiring dengan perubahan kepemimpinan di Amerika Serikat dan Jepang. Namun demikian mayoritas masyarakat Jepang masih percaya untuk bersekutu dengan Amerika Serikat.

Pada masa kepemimpinan Presiden Barrack Obama yang mengarahkan kebijakan "Pivot to ASIA", Pemerintah Jepang mendapatkan keuntungan sebagai sekutu. Amerika Serikat dihadapkan dengan kebangkitan Tiongkok. Di kawasan Asia, Tiongkok telah meningkatkan hegemoni yang signifikan. Para ahli seperti Joseph Nye memperkirakan bahwa hegemoni Amerika Serikat yang menurun akan digantikan oleh Tiongkok.

Di sisi lain, hubungan Jepang dan Tiongkok tidak begitu baik. Masyarakat Jepang dan Tiongkok saling tidak percaya satu sama lain dalam bidang keamanan. Sehingga sangat kecil kemungkinannya untuk Jepang beraliansi dengan Tiongkok.

Jepang dan Tiongkok memiliki masalah perebutan wilayah, yaitu Kepulauan Senkaku. Pada awalnya kepulauan ini dilupakan hingga ditemukan hasil penelitian yang menunjukan bahwa dasar laut dari Laut China Timur memiliki potensi terkandung simpanan gas dan minyak yang terkaya di kawasan Asia pada 1986 oleh peneliti gabungan dari Pemerintah Jepang, Korea Selatan dan Tiongkok. Selain itu, Kalangan nasionalis Jepang juga menganggap bahwa klaim wilayah yang dilakukan 
Tiongkok akan mengarah pada invansi terhadap daratan utama Jepang sebagai bentuk dari ancaman Tiongkok (China Threat). Menurut Pemerintah Jepang hal ini akan memicu masalah konflik wilayah dengan negara lain yang sedang dihadapi Jepang.

Klaim Pemerintah Jepang terhadap Kepulauan Senkaku berdasarkan pada beberapa bukti sejarah yang menyebutkan bahwa kepulauan Senkaku sebagai bagian dari wilayah Jepang, yaitu Jepang mentukan batas wilayah Kekaisaran Jepang pada Januari 1895, pada artikel yang dibuat oleh sebuah organisasi partai komunis Tiongkok menyebutkan bahwa kepulauan senkaku berada di dalam wilayah Jepang, perjanjian Shimonoseki yang mengakhiri perang sino-jepang tidak disebutkan kepulauan senkaku sebagai bagian dari Taiwan yang pada perjanjian itu diserahkan kepada Jepang sebagai harta pampasan perang, dan pada perjanjian perdamaian Jepang dan AS di San Fransisko disebutkan bahwa kepulauan senkaku dikembalikan kepada Jepang sebagai bagian dari wilayah Okinawa. Sedangkan klaim pemerintahan Tiongkok terhadap kepulauan senkaku adalah menuduh Jepang telah mencuri kepulauan senkaku pada perang sino-Jepang (Agustus 1894 - April 1895) dari kekaisaran Qing dan tidak mengakui perjanjian sanfransisco yang dianggap dilakukan secara rahasia antara pemerintah Jepang dan AS (The Senkaku Island, 2013).

Konflik semakin memanas ketika Pemerintah Jepang membeli tiga pulau yang termasuk ke dalam kepulauan Senkaku pada 11 September 2012 seharga 2,05 milyar yen yang diumumkan oleh Perdana Menteri yang menjabat saat itu yaitu Noda Yoshihiko. Tindakan pemerintah Jepang tersebut memperoleh respon negatif dari pemerintah Tiongkok di wilayah perairan dan udara Laut Cina Timur. Menurut data dari Ministry of Foreign Affair (MOFA) pemerintah Jepang terjadi kenaikan jumlah kapal milik Tiongkok yang memasuki wilayah perairan disekitar kepulauan Senkaku yang signifikan. Tahun 2009 sebanyak 16 kapal yang memasuki wilayah perairan Jepang, tahun 2010 meningkat tajam sebanyak 430, dan pada 2011 sebanyak 8 kapal, 2012 sebanyak 39 kapal, 2013 sebanyak 88 kapal, 2014 sebnyak 208 kapal, 2015 sebanyak 70 kapal dan 2016 sebanyak 104 kapal (Kementrian Luar Negeri Jepang yang berjudul "Status of activities by Chinese government vessels and Chinese fishing vessels in waters surrounding the Senkaku Islands " pada 2016).

Pada 7 September 2010, terjadi peristiwa penangkapan awak kapal berserta kapal nelayan Tiongkok yang memasuki wilayah perairan di sekitar Kepulauan Senkaku oleh Penjaga Pantai Jepang (Japan Coast Guard). Permasalahan terjadi ketika tiga kapal patroli Penjaga Pantai Jepang yang bernama Yonakuni, Mizuki dan Hateruma meminta kapal nelayan berhenti untuk diinspeksi, kapal nelayan Tiongkok tidak berhenti dan menabrak kapal yang bernama Yonakuni dan kemudian bertambrakan lagi dengan kapal yang bernama Mizuki, setelah berkejaran selama sekitar 40 menit kapal ikan Tiongkok tertangkap dan dijatuhi hukuman kepada Kapten kapal bernama Zhan Qixiong berserta anak buah kapal 
(ABK) lainnya oleh pemerintah Jepang atas kejahatan merusak dan menghalangi tugas Penjaga Pantai Jepang. Pemerintah Tiongkok meminta agar kapten kapal, ABK dan kapal ikan dibebaskan namun pemerintah Jepang menyerahkan kapten kapal dan ABK kepada jaksa penuntut umum agar dapat diproses secara hukum Jepang.

Pemerintah Tiongkok dengan cepat menanggapi masalah ini dengan mengajukan ke dalam agenda PBB dan juga melalui diplomasi dengan Jepang secara langsung. Pemerintah Tiongkok melakukan tawar menawar dengan empat orang warga negara Jepang yang ditangkap di Tiongkok dan pelarang ekspor material tanah yang langka (rare earth) yang sangat penting untuk industri Jepang. Empat karyawan perusahaan PT. Fujita dikirim ke Tiongkok untuk mendapatkan senjata yang ditinggalkan pada Perang Dunia Kedua 20 September 2010 dihukum karena memasuki daerah militer yang terlarang di provinsi Heibei. Selain itu, Pemerintah Tiongkok. Sehingga pada 24 September pengadilan Ishigaki membebaskan kapten kapal (Sasaki, 2015)

Selain itu, di wilayah udara terjadi peningkatan tajam dalam kurun waktu 2010-2015. Pada 23 Desember 2012-23 Maret 2014 tercatat sebanyak 13 kali pesawat jenis Y-12 milik State Oceanic Administration (SOA) pemerintah Tiongkok memasuki wilayah udara Jepang. Pada Januari 2013, Kementrian Pertahanan Nasional Tiongkok mengumumkan kegiatan pesawat PLA di Laut Cina Timur yang pada Juli pesawat peringatan dini udara Y-8 dan pesawat pembom H-6 dikonfirmasi berada di langit antara pulau utama Okinawa dan pulau Miyakojima ke arah Samudra Pasifik pada bulan Juli, September dan tiga hari berturut-turut pada November dan pesawat intelijen Tu-154 di Laut Cina Timur pada November selama dua hari berturut-turut (Jepang, 2014).

Selain Senkaku yang terletak di Laut China Timur, di Laut China Selatan pun Tiongkok memiliki masalah perebutan wilayah. Tiongkok pada 2012 mengklaim perairan Laut China Selatan yang merupakan kawawan Laut China Selatan. Kawasan Laut China Selatan meliputi perairan dan daratan yaitu gugusan kepulauan dua pulau besar (pulau Spratly dan pulau Paracels), bantaran suangai Macclesfield dan karang Scarborough. Laut China Selatan memiliki cadangan sumber daya alam yang besar seperti mineral, minyak bumi, dan gas alam dan juga memiliki lokasi yang strategis karena berada di jalur perlintasan internasional. Negara-negara yang mengklaim kawasan Laut China Selatan adalah Tiongkok, Vietnam, Filipina, Malaysia dan Brunei Darusalam.

Rizki Roza dalam penelitiannya yang berjudul Konflik Laut China Selatan dan Implikasinya terhadap Modernisasi Militer (2013) berpendapat bahwa negaranegara yang terlibat dalam sengketa kepemilikan Laut China Selatan sedang melakukan modernisasi kekuatan militer dengan sangat pesat dan berkelanjutan. Tiongkok sedang berupaya untuk melakukan program modrnisasi militer jangka panjang untuk meningkatkan kemampuan kekuatan bersenjata yang memungkinkan untuk bertempur dan menang dalam waktu singkat. 
Tiongkok memperbaharui sebanyak $84 \%$ senjatanya baru sejak 2009 yang diperlihatkan pada parade militer yang digelar oleh Pemerintah Tiongkok (Zhiyue, 2015). Dalam buku putih yang diterbitkan Kementrian Pertahanan Jepang Tiongkok merupakan salah satu negara yang memiliki senjata nuklir dan mempunyai misil yang berteknologi mutakhir. Tiongkok mempunyai misil dengan sistem ICBM, MRBM, SRBM dan GLCM. Jangkauan jarak misil balistik Tiongkok terjauh dapat mencapai $13.000 \mathrm{~km}$.

Selain anggaran belanja militer yang terus-menerus naik walaupun angka pertumbuhan ekonomi dari tahun 2016 berangsur-angsur menurun dan kepemilikan senjata pemusnah masal berupa senjata nuklir dan misil balistik. Jumlah pasukan militer Tiongkok merupakan peringkat kedua setelah Amerika Serikat dengan persenjataan yang makin modern.

Alat ukur tunggal dan terpenting untuk mengukur sumber daya dalam bidang militer untuk dibandingkan dengan negara lainnya adalah dengan melihat anggaran belanja militernya. Anggaran belanja militer Tiongkok berdasarkan pada besaran pertumbuhan ekonomi, sejalan dengan peningkatan prosentasi pertumbuhan ekonomi Tiongkok maka semakin besar pula anggaran belanja militernya. Sedangkan Jepang hanya boleh berkisar pada prosentase 1\% dari GDP. Sehingga pada tahun 2016 anggaran belanja Tiongkok adalah lima kali anggaran belanja Jepang. Perbandingan anggaran belanja militer Jepang dan Tiongkok tahun 20012017 adalah sebagai berikut:

Anggaran belaja Tiongkok terus-menerus meningkat dari tahun ke tahun sedangkan anggaran belanja Jepang berkisar pada 41 ribu dolar AS (Zhiyue, 2015). Dalam buku putih yang diterbitkan Kementrian Pertahanan Jepang menganggap bahwa Tiongkok kurang transparan dalam melaporkan anggaran belanja militer dan persenjataan militer Tiongkok setiap tahunnya.

Terlebih tanggapan Pemerintah Tiongkok terhadap proposal revisi UndangUndang Dasar Jepang 1947 khusunya Pasal 9 LDP tahun 2004 yang diumumkan melalui Xinhua News Agency mengatakan bahwa perubahan tersebut adalah peringatan untuk meningkatkan kewaspadaan dunia terutama negara-negara Asia yang dijajah oleh Jepang pada masa lalu. Menurut Tiongkok Jepang bermimpi untuk menjadi kekuatan militer dan politik yang akan menjadi ancaman serius untuk kedamaian di Asia dan dunia. Tiongkok mengungkit pemerintah Jepang yang tidak mengakui dan meminta maaf atas perbuatannya di masa lalu sehingga dapat dipastikan Jepang akan melakukan hal yang sama lagi jika Jepang memiliki kekuatan militer kembali. Batasan-batasan yang telah ditetapkan dilanggar oleh Pemerintah Jepang dengan mengizinkan Pasukan Bela diri Jepang pergi ke luar wilayah Jepang dan secara sengaja melakukan serangan ke barbagai negara yang dianggap musuh yang dilakukan untuk pencegahan.

Dalam bidang ekonomi, Jepang dihadapkan dengan inisiasi Presiden Xi Jinping yang disebut One Belt One Road (OBOR). OBOR adalah inisiasi strategi geopolitik Tiongkok dengan pemanfaatan jalur transportasi dunia sebagai jalur 
perdagangan yang tersebar di kawasan Eurasia. untuk meningkatkan kesejahteraan dan perwujudan modernisasi Tiongkok di tahun 2020 dengan meningkatkan intensitas perdagangan dengan penyediaan fasilitas infrastruktur lewat darat maupun laut (Izuyama \& Kurita, 2017).

Terdapat dua jalur perdagangan dalam skema inisiatif OBOR yang dikemukakan oleh Presiden Tiongkok Xi Jinping yaitu di jalur darat disebut dengan "Jalur Ekonomi Jalan Sutra" (Silk Road Economic Belt) dan "Jalur Sutra Maritim Abad Ke-21" (21st century Maritime Silk Road). Negera-negara yang termasuk ke dalam Inisiatif OBOR adalah Tiongkok, Brunei, Kamboja, Indonesia, Laos, Malaysia, Myanmar, Filipina, Singapura, Thailand, Timor-Leste, Vietnam, Bangladesh, Bhutan, India, Maladewa, Nepal, Pakistan, Sri Lanka, Afghanistan, Armenia, Azerbaijan, Georgia, Iran, Kazakhstan, Kyrgyzstan, Mongolia, Tajikistan, Turkmenistan, Uzbekistan, Bahrain, Mesir, Irak, Israel, Yordania, Kuwait, Lebanon, Oman, Palestina, Qatar, Arab Saudi, Republik Arab Suriah, Turki, Amerika, Arab Emirates, Yemen, Albania, Belarus, Bosnia \& Herzegovina, Bulgaria, Kroasia, Republik Ceko, Estonia Hungaria, Latvia, Lituania, Makedonia, Moldova, Montenegro, Polandia, Rumania, Rusia, Serbia, Slowakia, Slovenia dan Ukraina (Enright, 2016).

Tingkok akan menjadi pemimpin dalam perdagangan bebas melalui OBOR. Contoh yang paling baik untuk memperlihatkan peningkatan industri Tiongkok yang menggunakan OBOR, sekaligus rasa ketidakamanan Jepang dalam bidang ekonomi adalah strategi diplomasi yang disebut sebagai "diplomasi kereta api cepat" (High-Speed Railway Diplomacy). Tiongkok dapat mempromosikan teknologi tingkat tinggi dan standar insinyur pada bidang kereta cepat melalui projek kereta api cepat Jakarta-Bandung sepanjang 142 kilometer yang menghubungkan Ibukota Indonesia dengan provinsi Jawa Barat. Proses negosiasi proyek kereta api cepat Jakarta-Bandung merupakan medan pertarungan yang sengit antara Pemerintah Tiongkok dan Jepang. Proyek kereta api cepat JakartaBandung merupakan hal yang penting bagi kedua negara. Untuk proyek kereta cepat Jakarta-Bandung merupakan awal dari rencana Tiongkok untuk membangun jaringan kereta api cepat di seluruh dunia yang merupakan bagian dari Inisiasi OBOR. Rencana serupa akan dilakukan Malaysia, Singapura, Myanmar, Vietnam, dan India (Salim \& Negara, 2016).

Menurut Rachel Vandenbrink (2017) dalam artikel penelitian yang berjudul Asia's Turn to Geopolitics: China and Japan in Central and Southeast Asia berpendapat bahwa "terdapat persaingan yang sengit antara Tiongkok dan Jepang dalam kerangka geopolitik." Lebih lanjut menegaskan bahwa " sementara inisiatif OBOR Beijing meningkatkan posisi Tiongkok di perbatasan Asia Tengah dan Asia Tenggara, Jepang menggunakan prinsip geopolitik untuk meningkatkan kepentingannya sendiri di wilayah yang sama dan memastikan tidak tertinggal" (Vandenbrink, 2017). 
Terdapat persaingan antara Jepang dan Tiongkok di Asia. Langkah Tiongkok selalu diikuti dengan ketat oleh Jepang. Upaya Jepang untuk menghalangi Tiongkok menjalankan inisiatif OBOR yang nantinya akan menjadikan Tiongkok menjadi negara adikuasa menggatikan kekuasaan Amerika Serikat yang mengalami peneurunan hegemoni salah satunya adalah dengan menjalin hubungan yang baik dengan negara-negara yang menjadi anggota inisiatif OBOR.

Melihat kemungkinan Tiongkok mengusai ekonomi dunia, Abe Shinzo sebagai Perdana Menteri Jepang mengeluarkan startegi yang mirip dengan inisiatif OBOR Tiongkok dengan empat negara yaitu Amerika Serikat, Australia dan India yang akan membangun pelabuhan dan jaringan jalan berkecepatan tinggi di Asia ke Afrika. Amerika Serikat memberikan tawaran untuk membangun jalan di Bangladesh ke Afghanistan sehingga bahkan Pakistan dapat diminta untuk berpartisipasi dalam proyek ini. Tujuannya adalah agar keempat negara menjadi empat jangkar keamanan dan perdamaian di wilayah Indo-Pasifik. Proposal ini adalah upaya Jepang menghalau OBOR Tiongkok (Hindustan Times, 2017).

Selain ancaman dari Tiongkok, Jepang juga merasakan ancaman dari Korea Utara. Setelah kematian Kim Jong-Il tepatnya pada 29 Januari 2012, kepala negara Korea Utara diteruskan oleh anak Kim Jong-Il yang bernama Kim Jong-Un. Pergantian kepemimpinan Korea Utara dijadikan peluang untuk membahas ulang nuklir Korea Utara yang pada masa pemerintahan Kim Jong-Il mengalami kebuntuan oleh anggota Six Party Talk (SPT), yaitu perundingan enam negara (Korea Utara, Korea Selatan, Jepang, Rusia dan Amerika Serikat) yang dibentuk untuk membahas mengenai nuklir Korea Utara. Pada pertemuan SPT Kim Jong-Un meminta bantuan pangan dan berjanji akan menghentikan uji coba nuklir, memproduksi uranium dan uji coba misil jarak jauh.

Akan tetapi, hal ini hanya berlangsung selama satu tahun, pada Februari 2013 pemerintah Korea Utara melalui media pemerintahan mengumumkan akan memulai kembali seluruh fasilitas nuklir di Yeongbyon. Pada September 2015, seluruh fasilitas tersebut telah beroperasi secara normal.

Uji coba peluncuran rudal oleh Korea Utara semakin banyak intensitasnya pada rezim Kim Jong-Un. Pada 2016 Korea Utara telah meluncurkan rudal sebanyak 15 kali. Pada 7 Februari 2017 Korea Utara meluncurkan rudal yang diperkirakan adalah rudal berjenis Taepodong-2 yang memiliki jarak luncur sampai $1.000 \mathrm{~km}$ (dapat mencapai wilayah Amerika Serikat). Dua kali pelincuran telah memasuki wilayah Zona Ekonomi Esklusif (ZEE) Jepang, tanggal 3 Agustus 2016 jatuh ke sekitar semenangjung Oga di Perfektur Akita, dan pada 5 September 2016 juga jatuh di wilayah ZEE Jepang yaitu dekat dengan pulau Okushiri di Hokaido.

Pada pertengahan tahun 2016, Korea Utara juga meluncurkan serangkaian uji coba rudal yang mengalami kemajuan pada setiap peluncurannya. Yaitu pada 23 April, 9 Juli dan 24 Agustus 2016 yaitu rudal balistik yang diluncurkan dari kapal selam yang dikenal dengan istilah Submarine-Launched Balistic Missiles (SLBMs). Korea Utara meluncurkan rudal SLBMs pada 23 April yang berhasil meluncur 
sejauh $30 \mathrm{~km}$, kemudian mengalami kegagalan pada peluncuran tanggal 9 Juli karena seketika meledak setelah diluncurkan, dan mulai meningkat pada peluncuran tanggal 24 Agustus yang meluncur sejauh $500 \mathrm{~km}$.

Selain uji coba rudal, Korea Utara juga sedang mengembangkan senjata nuklir. Terdeteksi Korea Utara sudah melakukan uji coba nuklir sebanyak lima kali. Uji coba nuklir yang pertama dan kedua yaitu pada 9 Oktober 2006 dan 25 Mei 2009 menghasilkan kurang dari 3 kiloton dibawah rezim Kim Jong-Il. Pada masa Kim Jong-Un berkembang menjadi 12 kiloton yang dihasilkan pada 9 September 2016, yang sebelumnya pada 6 Januari 2016 dan pada 12 Februari 2013 menghasilkan sampai 7 kiloton (Erik Isaksson, 2017). Korea Utara akan mencapai bom "Litle Boy" dan "Fat Man" yang dijatuhkan di Hiroshima dan Nagasaki oleh Amerika serikat pada Perang Dunia II yang menghasilkan 15 kiloton dan 21 kiloton (Murooka dan Akutsu, 2017).

Jepang mulai mengembangkan sistem pertahanan terhadap misil balistik (BMD) pada 2004. Pada 2007 Kementrian Pertahanan Jepang mulai menyebar PAC-3 (the Patriot Advanced Capability-3) yang merupakan salah satu sistem pertahanan udara untuk membalas ancaman dari udara yang dirancang untuk menangkap misil balistik. Dan pada 2016 memiliki 24 buah aki untuk PAC-3 dan enam buah pertahanan misil balistik yang berpusat pada laut (Jepang, 2014).

Faktor eksternal yang dipaparkan di atas dijadikan alat oleh Pemerintah Jepang untuk menggiring pandangan masyarakat Jepang terhadap wacana Amandemen Pasal 9 Undang-Undang Dasar Jepang 1947. Namun di sisi lain, ketakutan Jepang akan memperburuk hubungan dengan Tiongkok dan Korea Utara juga dikhawatirkan oleh masyarakat Jepang.

\section{Kesimpulan}

Tekanan luar atau gaiatsu mempengaruhi dinamika wacana amademen pasal 9 Undang-Undang Dasar Jepang 1947 di level domestik. Perdana Menteri Jepang mencoba menggunakan isu-isu ancaman keamanan global untuk mendorong kebijakan Jepang seperti kemajuan militer Tiongkok dan misil balistik dan nuklir Korea Utara untuk mendorong opini masyarakat agar dapat mengamandemen pasal 9 UndangUndang Jepang 1947. Namun di lain pihak, adanya kekhawatiran remiliterisasi Jepang dapat memicu perang dengan negara di kawasan, terutama Tiongkok.

Kemajuan militer dan ekonomi Tiongkok memungkinkan Tiongkok untuk menjadi adidaya. Hubungan Jepang dan Tiongkok yang saling bersaing, menjadikan Jepang terus memperkuat aliansi dengan Amerika Serikat. Jepang terus menerus menghalau Tiongkok. Contohnya Jepang membuat strategi tandingan untuk inisiatif OBOR Tiongkok dengan mengandeng negara-negara yang tidak terlibat dengan OBOR, yaitu Amerika Serikat, India dan Australia.

Hegemoni Amerika Serikat di dunia mengalami kemunduran pasca tragedi 9/11. Keterlibatan Amerika Serikat pada Perang Afganistan dan Iraq telah menghabiskan energi dan waktu Amerika Serikat. Stagnansi pertumbuhan Ekonomi Amerika Serikat 
Igat Meliana

menyebabkan krisis ekonomi yang dialami oleh Amerika Serikat. Di tengah kondisi Amerika Serikat yang mulai kehilangan kekuatannya, mayoritas masyarakat Jepang masih percaya untuk menjadikan Amerika Serikat sebagai sekutu. Walau pun demikian, sebagian masyarakat tidak menginginkan Jepang untuk menjadi negara yang memiliki militer dan berlindung di bawah payung keamanan Amerika Serikat. 
Faktor Eksternal Yang Mempengaruhi Dinamika Wacana Amandemen Pasal 9 UndangUndang Dasar Jepang 1947

\section{BIBLIOGRAFI}

Enright, Scott. (2016). One Belt One Road: Insights for Finland. Team Finland Future Watch Report.

Erik Isaksson, Lars Vargö and Liam Palmbach. (2017). Japan and North Korea: Toward Engagement for Regional Security. Institute for Security and Development Policy, 206, 1-3. Retrieved from https://isdp.eu/content/uploads/2017/10/2017-isakssonvargo-palmbach-japan-north-korea-regional-security.pdf

Hyodo, Shinji. (2017). East Asian Strategic Review 2017. Tokyo.

Island, The Senkaku. (2013). Ministry of Foreign Affairs. Retrieved from http://www.mofa.go.jp/region/asia-paci/senkaku/pdfs/senkaku_en.pdf

Izuyama, Mari, \& Kurita, Masahiro. (2017). Security in the Indian Ocean Region: Regional Responses to China's Growing Influence. East Asian Strategic Review.

Jepang, Kementrian Pertahanan. (2014). China's activities surrounding Japan's airspace diakses dari pada. Retrieved from http://www.mod.go.jp/e/d_act/ryouku/

Oh, Hyun. (2016). Sirens blare as Japan, fearing N Korea, holds first missile drill. Retrieved from https://japantoday.com/category/national/sirens-blare-as-japanfearing-n-korea-holds-first-missile-drill

Salim, Wilmar, \& Negara, Siwage Dharma. (2016). Why is the high-speed rail project so important to Indonesia.

Sasaki, Alexandra. (2015). Japan's Security Policy: A shift in Direction under Abe?. Terj. David Barnes. SWP-Studie 21/2014. Berlin: Stiftung Wissenschaft und Politik German Institute for International and Security affairs. Retrieved from https://www.swpberlin.org/fileadmin/contents/products/research_papers/2015_RP02_skk.pdf

Smith, Sheila. (2016). Voters give Abe an opening for contitutional debate. Retrieved from http://forbes.com/sites/sheilaasmith/2016/07/11/voters-give-abe-an-openingfor-constitutional-debate/amp/\#amph=1

Statistics, U. S. Bureau of labor. (2012). Biro Tenaga Kerja Kementrian Tenaga Kerja Amerika Serikat. diakses dari pada. Retrieved from https://data.bls.gov/pdq/SurveyOutputServlet

Times, Hindustan. (2017). Japan to propose OBOR-like project with India, US to counter China. Retrieved from http://www.hindustantimes.com/india-news/japanto-propose-obor-like-project-with-india-us-to-counter-china/storyA3jsZBRAuQ5yM8pEPYEDPP.html

Vandenbrink, Rachel. (2017). Asia's Turn to Geopolitics: China and Japan in Central and Southeast Asia. Retrieved November 18, 2017, from 
Igat Meliana

http://web.isanet.org/Web/Conferences/HKU2017-s/Archive/77c581ce-94fe-4c91815d-b5f337400688.pdf

Widyasari, Lilis. (2014). Dinamika hubungan Korea Selatan-Korea Utara dalam mewujudkan reunifikasi di Semenanjung Korea periode 2003-2008Widyasari, Lilis. (2014). Dinamika hubungan Korea Selatan-Korea Utara dalam mewujudkan reunifikasi di Semenanjung Korea periode 2003-2008.

Zhiyue, Bo. (2015). 3 Takeaways From China's Military Parade. Retrieved November 8, 2017, from The Diplomat website: https://thediplomat.com/2015/09/3-takeawaysfrom-chinas-military-parade/ 